\title{
Performance Analysis of Grid connected Wind Energy Conversion System with a DFIG during Fault Condition
}

\author{
Sasi.C \\ Assistant Professor \\ Department of Electrical Engineering \\ Annamalai University \\ Chidambaram, India
}

\author{
G.Mohan, PhD. \\ Professor \\ Department of Electrical Engineering \\ Annamalai University \\ Chidambaram, India
}

\begin{abstract}
Integration of wind turbine based on doubly fed induction generator (DFIG) into the electrical grid has become an important part of electrical generation in many countries and its importance is continuing to increase. A few of them are various speed generations, the decoupled control of active and reactive power and high power capacity. The current and future wind power situation is modeled as two cases and short circuit faults in the system are simulated. The simulations yield information on (i) how the faults impact on the wind turbines and (ii) how the response of the wind turbines influences the post-fault behavior of the power system. Here, we attempted to compare the impact, in terms of voltages, active and reactive power, of adding wind turbines into electrical power grid. Therefore, the analysis of wind power dynamics with the DFIG wind turbines has become a very important research issue, especially during transient faults.
\end{abstract}

\section{Keywords}

Doubly Fed Induction Generator, Wind Turbine,

\section{Nomenclature}

$\begin{array}{ll}\text { DFIG } & \text { Doubly Fed Induction Generator } \\ \text { WECS } & \text { Wind Energy Conversion System } \\ \omega_{\mathrm{B}} & \text { Rotational speed of turbine } \\ \mathrm{P}_{\mathrm{w}} & \text { Power from the wind } \\ \mathrm{P} & \text { Air density } \\ \mathrm{R} & \text { Blade radius } \\ \mathrm{V}_{\omega} & \text { Wind speed } \\ \mathrm{C}_{\mathrm{p}} & \text { Power coefficient } \\ \lambda & \text { Tip speed ratio } \\ \beta & \text { Blade pitch angle } \\ \mathrm{u} & \text { Voltage } \\ \mathrm{R} & \text { Resistance }\end{array}$

\section{INTRODUCTION}

Wind energy is the fastest growing and most widely utilized emerging renewable energy technologies in electrical energy conversion systems at present [1]. This high penetration of wind energy in the power system has been closely related to the advancement of the wind turbine technology and the way of how to control. There are basically three types of generators that are commonly used with commercial wind turbines. They are (1) fixed-speed system with squirrel-cage induction generator, (2) variable-speed system with DoublyFed Induction Generator (DFIG) (3) variable-speed system with a direct-drive synchronous generator. DFIG based variable speed wind energy conversion systems are currently the most admired one, due to its important advantages such as, high capacity with high energy efficiency, four-quadrant active and reactive power controls and the small converter size with a rating of only $20 \%-30 \%$ of the rated Wind turbine power [2].

The control aspect of DFIG is decided by two back to back converter placed on rotor side. In this, constant-frequency ac grids are used, whereas primary mechanical power sources such as a dc machine usually operate at variable speed [3] [6]. Indeed, they are used in small-scale generators in windmills for instance. However, specific applications, such as aircraft, require higher level reliability and/or long-time maintenance periodicity. The power converter need only be rated to handle the rotor power [7]. To satisfy the grid code requirements of wind turbine, usually grid side converter is playing a major role. Independent control of active and reactive power from the grid or to the grid is possible by vector control of line side converter [8].

This paper considers the mutual effects of wind power in power systems under transient fault situations. It is analyzed (i) what impact the wind turbines have on the dynamic behavior of the system experiencing a fault and (ii) how the wind turbines behave in the system when it experiences a transient fault[9]- [11]. If transient faults in the system lead to considerable excursions in voltage and/or frequency the wind turbines were to disconnect and to reconnect only once the system has returned to stable operation. Increasing wind power penetration leads to the problem that considerable amount of generation might disconnect in case of a transient fault in the system, causing the system to become unstable from an otherwise harmless fault situation [12] \& [13]. To prevent such situations newly installed wind turbines have to comply with new grid connection requirements that demand wind turbines to ride through transient faults. This paper presents the dynamic behavior of the power system during transient faults, when wind energy is connected to the existing power system.

\section{POWER SYSTEM MODEL INTEGRATED WITH WIND FARM USING DFIG}

Dynamic model of a DFIG wind turbine can be represented in terms of the equations of each of the subsystems, mainly the turbine, the drive train, the induction generator and the control system. WECS considered for analysis consist of a DFIG driven by a wind turbine, rotor side converter, DC to DC intermediate circuit and grid side converter as shown in Fig.1. 


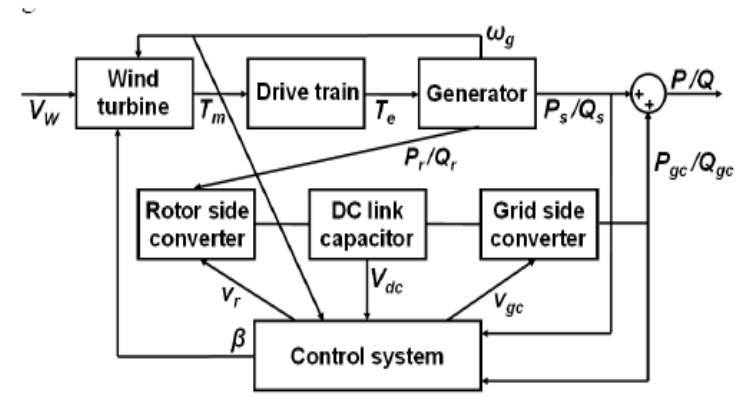

Fig.1: Components of DFIG Wind Turbine

The turbine output power is controlled in order to follow a pre-defined power-speed characteristic, named tracking characteristic. The electrical output power at the grid terminals of the wind turbine is added to the power losses and is compared with the reference power obtained from the tracking characteristic. In rotor side converter system, AC voltage and VAR are regulated. DC to DC intermediate circuit consists of two converters: Converter 1 (DC to AC) and Converter 2 (AC to DC). The control system of DC to DC intermediate circuit consists of DC voltage and current regulation and pitch control system. The pitch angle is regulated at zero degree by pitch angle regulator until the speed reaches desired speed of the tracking characteristic. The DC voltage output from intermediate circuit is applied to grid side converter, which consists of an Insulated Gate Bipolar Transistor (IGBT) two-level inverter, generating AC voltage at $50 \mathrm{~Hz}$. The IGBT inverter uses Pulse Width Modulation (PWM) at $2000 \mathrm{~Hz}$ carrier frequency. A $9 \mathrm{MW}$ wind farm consisting of six $1.5 \mathrm{MW}$ wind turbines connected to $440 \mathrm{~V}$ distribution system through power electronic interface. The wind speed is maintained constant at $15 \mathrm{~m} / \mathrm{s}$. Half of the world's leading wind turbine manufacturers use the DFIG systems. This is due to the fact that the power electronic converter only has to handle a fraction $(20 \%-30 \%)$ of the total power, i.e., the slip power. This means that if the speed is in the range $\pm 30 \%$ around the synchronous speed, the converter has a rating of $30 \%$ of the rated turbine power, reducing the losses in the power electronic converter, compared to a system where the converter has to handle the total power. In addition, the cost of the converter becomes lower. The WECS considered for analysis consist of a DFIG.

The mechanical power available from a wind turbine

$$
\begin{gathered}
P_{w}=0.5 \rho \Pi R^{2} V_{\omega}^{3} C_{p}(\lambda, \beta) \\
C_{p}=\frac{1}{2} \times\left(\lambda-0.022 \times \beta^{2}-5.6\right) \times e^{-0.17 \lambda} \\
\lambda=\frac{V_{\omega}}{\omega_{B}}
\end{gathered}
$$

where $P_{w}$ is the extracted power from the wind, $\rho$ is the air density, $R$ is the blade radius and $V_{\omega}$ is the wind speed. $C_{p}$ is called the 'power coefficient' and is given as a nonlinear function of the parameters tip speed ratio $\lambda$ and blade pitch angle $\beta$. The calculation of the performance coefficient requires the use of blade element theory. $\omega_{B}$ is the rotational speed of turbine. Usually $\mathrm{C}_{\mathrm{p}}$ is approximated as,

$$
C_{p}=\alpha \lambda+\beta \lambda^{2}+\gamma \lambda^{3}
$$

where $\alpha, \beta$ and $\gamma$ are constructive parameters for a given turbine. The torque developed by the windmill is

$$
T_{t}=0.5 \mu\left(\frac{C_{p}}{\lambda}\right) \cdot V_{\omega}^{3} u R^{2}
$$

The reactive power produced by the wind turbine is regulated at 0 MVAR. This model is well suited for observing harmonics and control system dynamic performance over relatively short periods of times. Power system model [14] is used.

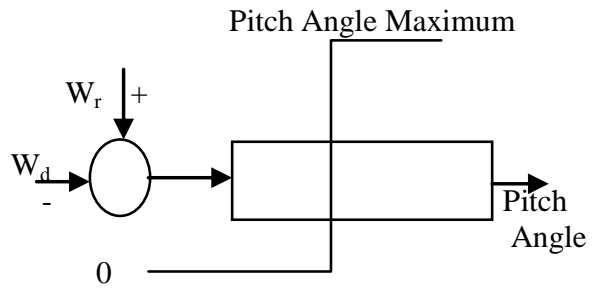

Fig.2: Pitch Angle Control System

The protection system that disconnects the turbines in case of a fault is implemented in the form of under voltage, overs peed and over current protection. The protection scheme implemented in this model disconnects the generator and its compensation unit, when the voltage at the generator terminals drops below $0.75 \mathrm{pu}$ for $100 \mathrm{~ms}$; the speed of the generator exceeds $105 \%$ of its rated speed (when the generator cannot export as much power as is imported through the wind, it accelerates); the voltage exceeds $1.1 \mathrm{pu}$ for 100 $\mathrm{ms}$, the instantaneous $\mathrm{AC}$ over current exceeds $10 \mathrm{pu}$., the maximum AC current exceeds 1.1 pu., the maximum AC current unbalance exceeds 0.4 times maximum AC current., the maximum $\mathrm{AC}$ voltage unbalance exceeds 0.05 times maximum voltage.

The Power Coefficient $\mathrm{Cp}$ v/s Curves for Various Values of Pitch Angles are shown in Fig.3. Fig.4 shows turbine output power $\mathrm{v} / \mathrm{s}$ turbine speed for pitch angle $0 \mathrm{deg}$.

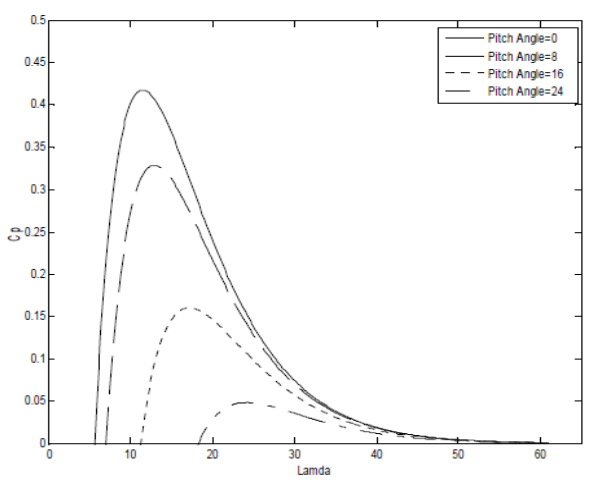

Fig.3: Power Coefficient $C_{p}$ vs Lambda 


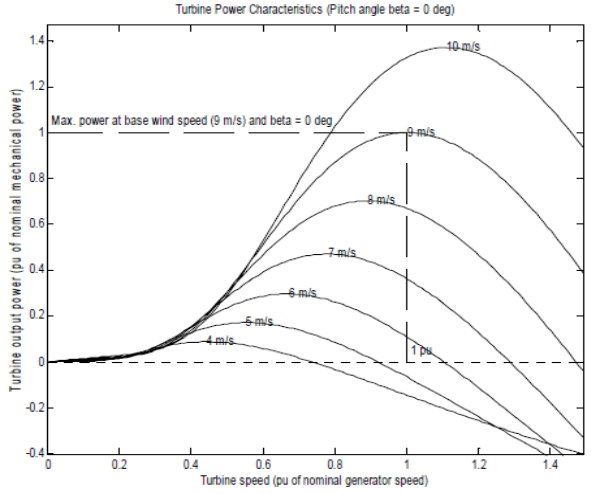

Fig.3: Wind Turbine Power Characteristics

\section{RESULTS AND DISCUSSIONS}

The simulation result shows the characteristic waveforms of the stator voltage, stator current, active power, reactive power, dc-link voltage, rotor speed under steady state condition. It is observed that the active and reactive powers supplied by the utility grid are decoupled and dc link voltage is maintained constant due to the control strategy made in the grid side converter. Different scenarios are simulated to assess the impact of wind power on integration with power grid. The faults simulated are $104 \mathrm{~ms}$, zero impedance; phase to phase short circuits on $132 \mathrm{KV}$ line. The fault gets cleared by permanent disconnection of the faulted line. This is a fault situation described in Elkraft's grid connection requirements for wind farms connected to the transmission system.

Case I: The situation which is simulated here is that the wind turbines are not connected to the transmission system. A phase to phase fault is simulated on $132 \mathrm{KV}$ line i.e. bus B5 at $\mathrm{t}=5 \mathrm{sec}$. for $104 \mathrm{~ms}$. Fig. 4 shows that the voltage at busbar B5 drops to zero, as it is closest to the fault location. Bus B6 is hardly affected by this fault as it is far away from the fault. The voltage at B5 gets suppressed in the beginning of the fault and after a few ms it recovers quickly after the clearance of the fault which means that they do not consume reactive power any more. The voltage at B4 recovers also relatively quickly because of the reduced reactive power demand in the first seconds.

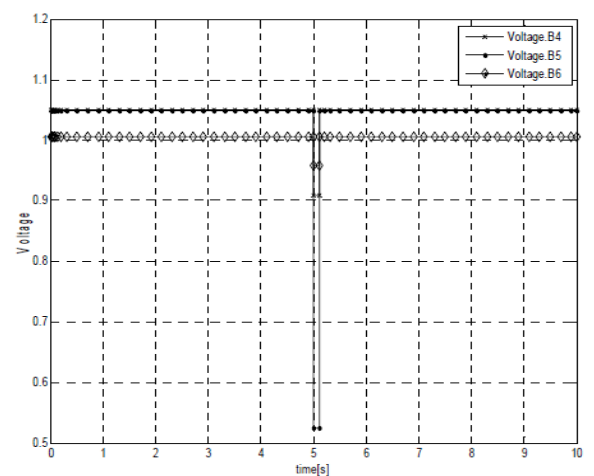

Fig.4: Voltage at different location in power system

Case -II: Here the situation is simulated that 9 MW wind farm has been connected to power system. The fault conditions are kept same as before. There is substantial drop in voltage at wind turbines due to fault and wind turbine WT1 trips due to operation of protection system of turbines, which disconnects wind turbine WT1 due to AC under voltage at $\mathrm{t}=5.112 \mathrm{sec}$.
After the clearance of fault, the voltage recovers to normal position in the system. Fig.5 shows voltage at different locations during present case. The fault excites the inherently flexible drive train of the wind turbines to oscillations, which in the first instances after the clearance of the fault leads to a strongly reduced active power production. At the same time the compensation capacitors stay connected helping the voltage to recover. Fig.6 and Fig. 7 shows active and reactive power of wind turbines.

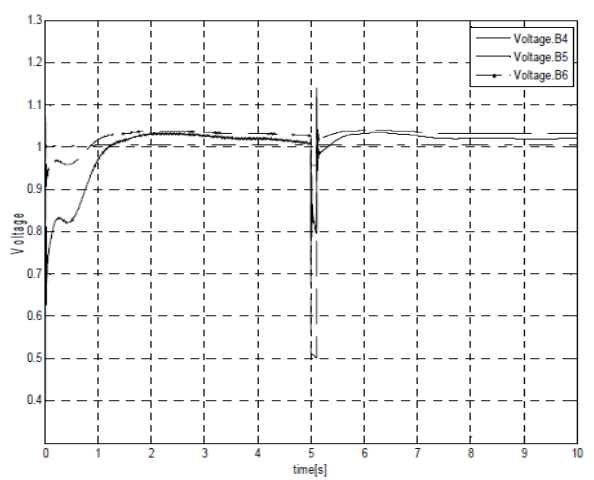

Fig.5: Voltage at different location in power system

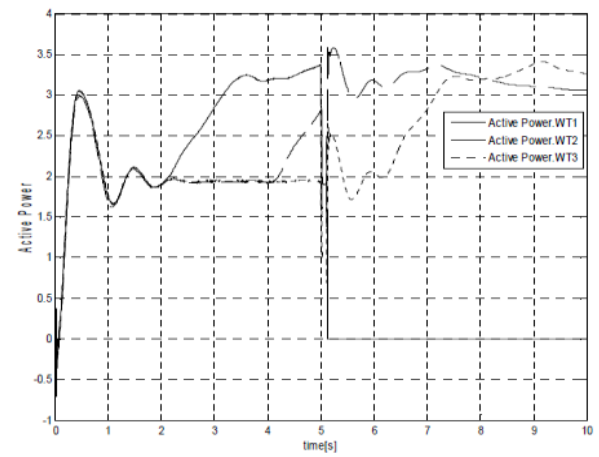

Fig.6: Active Power at Wind Turbines 1, 2 \&3

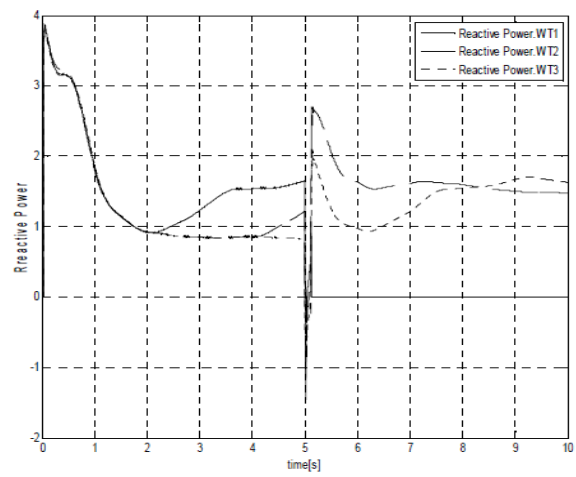

Fig.7: Reactive Power at Wind Turbines 1, 2 \&3

Comparison of Cases I and II

As noted above, the voltage variations caused by the faults, simulated in the different cases, has a negligible impact on the power system. The frequency and hence the active power flow through the system gets affected though. An effective means of comparing the consequence of the different scenarios on the power system is comparing the active and reactive powers in the system. Fig.8-10 shows the comparison of active power at buses B4, B5 and B6 for Cases-I and II. It is observed that 
variation in active power at buses B4, B5 and B6 for Case-I which do not include wind turbines, is very less as compared to Case-II. The variation is about -0.05 to +0.05 for buses B4 and B5 and -0.3 to 0.1 for bus B6 during phase to phase fault for Case-I and hence cannot be predicted clearly while comparing with Case-II. The active power at buses in Case-II has a dip during fault, but oscillations die out quickly in approx. 2 secs. Fig.11-13 shows the comparison of reactive power at buses B4, B5 and B6 for various cases. The reactive power at bus B6 is most affected during A-B fault at $\mathrm{t}=5 \mathrm{sec}$, but oscillations die out quickly after the clearance of fault.

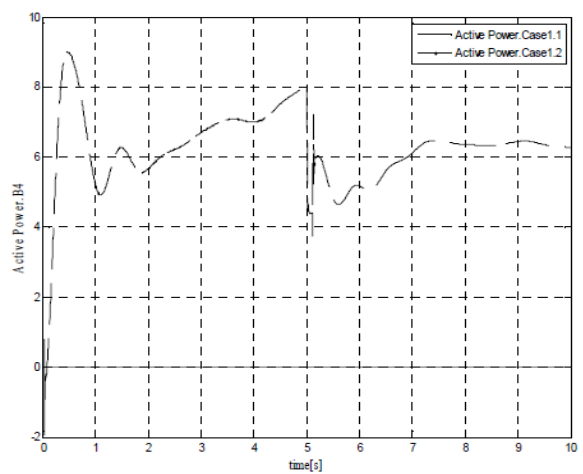

Fig.8: Active Power at Bus B4 during different Cases

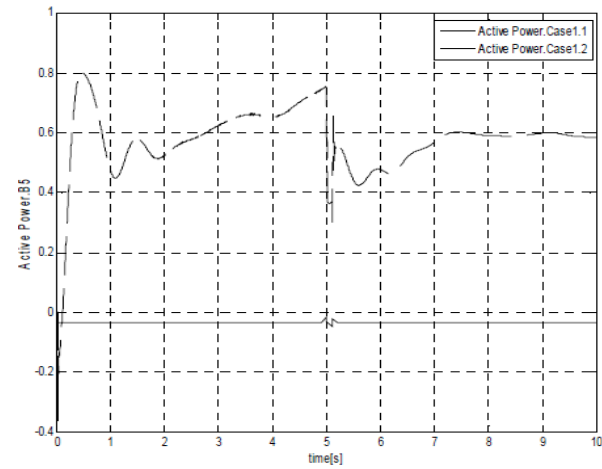

Fig. 9: Active Power at Bus B5 during different Cases

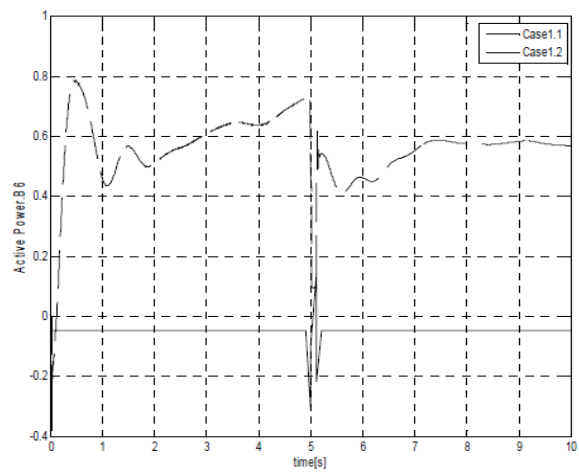

Fig. 10: Active Power at Bus B6 during different Cases

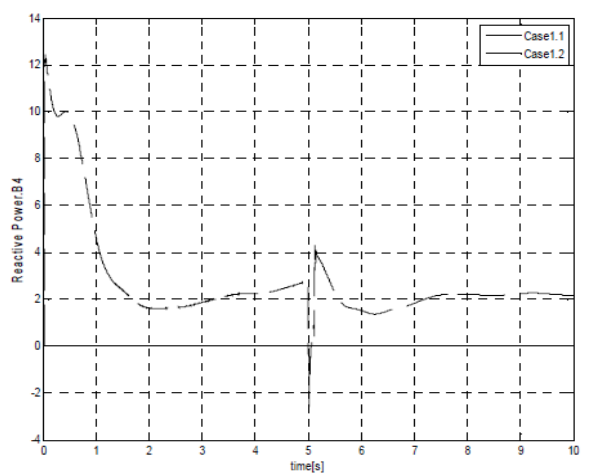

Fig. 11: Reactive Power at Bus B4 during different Cases

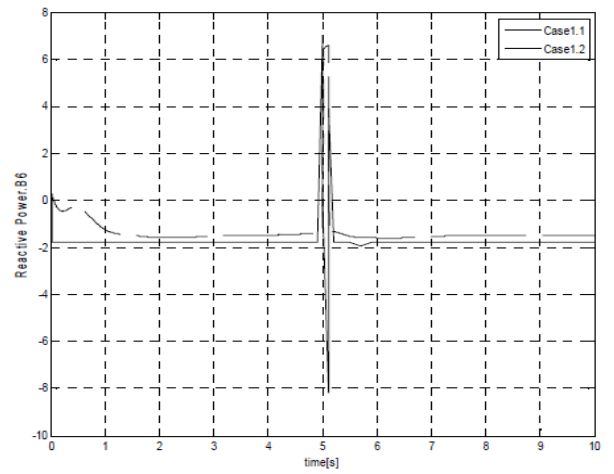

Fig. 12: Reactive Power at Bus B6 during different Cases

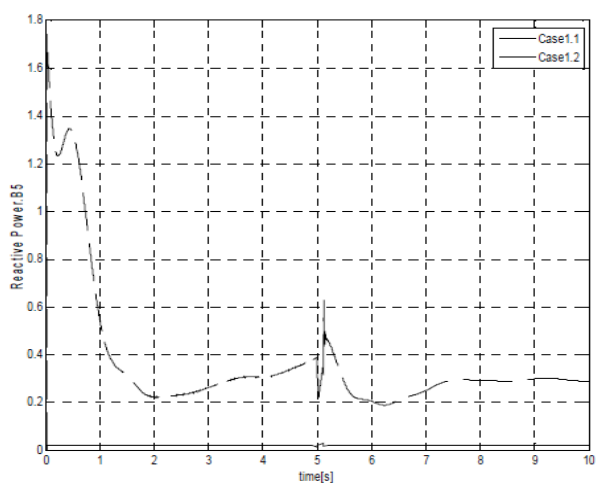

Fig. 13: Reactive Power at Bus B5 during different Cases

\section{CONCLUSION}

The system performance analysis is done under steady state and for a sudden change in grid voltage. The generated stator voltages and currents, active power supplied to grid, VAR requirement for the DFIG are observed and it is concluded that with the implemented vector control strategy, the doubly fed induction generator system under simulation study is suitable under sudden change in grid voltage. This paper has presented the analyzed results on transients of a small wind power generation system connected to a low voltage power grid. Two different cases are considered examining the influence of adding $9 \mathrm{MW}$ wind farm to the power system. A transient phase to phase fault was simulated and its impact on the system voltage, active and reactive power at different 
locations in power system was investigated. The local voltage depression can hardly be noticed in other parts of the transmission system. It does however upset the wind turbines in the vicinity and cause their flexible drive trains to exhibit torsional oscillations. These oscillations manifest themselves in power fluctuation. Such power fluctuations are not only local effects but propagate through the system. It has been proven that with the inclusion of wind turbines equipped with sufficient control mechanisms, the performance of power system improves.

\section{ACKNOWLEDGMENTS}

The authors wish to thank the authorities of Annamalai University, Annamalainagar, Tamilnadu, India for the facilities provided to prepare this paper.

\section{REFERENCES}

[1] Bhim Singh and Shailendra Sharma "Stand-Alone Wind Energy Conversion System with an Asynchronous Generator" Journal of Power Electronics, Vol. 10, No. 5, September 2010.

[2] Sol-Bin Lee, Kyo-Beum Lee, Dong-Choon Lee and Jang-Mok Kim "An Improved Control Method for a DFIG in a Wind Turbine under an Unbalanced Grid Voltage Condition", Journal of Electrical Engineering \& Technology Vol. 5, No. 4, pp. 614 622, 2010.

[3] H. Akagi, "Active Harmonic Filter," In: Proceedings of the IEEE, 2005, pp. 2128-2141.B. and Plate, J. 2000.

[4] J. Arrillaga and N. R. Watson, Power System Harmonics, 2nd ed. NJ:Wiley, 2003.

[5] Lian, K. L. Noda, T.," A Time-Domain Harmonic Power-Flow Algorithm for Obtaining Nonsinusoidal Steady-State Solutions", In: IEEE Transactions on Power Delivery, Issue 99, 2010.

[6] S. A. Papathanassiou, "A Technical Evaluation Framework for the Connection of DG to the Distribution Network," In: Electr. Power Syst. Res., Jan. 2007, Vol. 77, No. 1, pp. 24-34.
[7] D. Schulz, R. Hanitsch, K. Moutawakkil, and C. Saniter, "Power Quality Behavior of Large Wind Parks with Variable Speed Wind Energy Converter,"CIRED, Barcelona, Spain, 2003.

[8] T. Thiringer, T. Petru, and C. Liljegren, "Power Quality Impact of a Sea Located Hybrid Wind Park," In: IEEE Trans. Energy Conversion, Jun. 2001, Vol. 16, No. 2, pp. 123-127.

[9] S. A. Papathanassiou and M. P. Papadopoulos, "Harmonic Analysis in a Power System with Wind Generation," In: IEEE Trans. Power Del., Vol. 21, No. 4, Oct. 2006, pp. 2006-2016.

[10] V.M.Moreno, M. Liserre, A. Pigazo, and A. Dell'Aquila, “A Comparative Analysis of Real-Time Algorithms for Power Signal Decomposition in Multiple Synchronous Reference Frames," IEEE Trans. Power Electron., Jul. 2007, Vol. 22, No. 4, pp. 1280 1289.

[11] R. S. Herrera, P. Salmeron, and H. Kim, "Instantaneous Reactive Power Theory Applied to Active Power Filter Compensation: Different Approaches, Assessment, and Experimental Results," In: IEEE Trans. Ind. Electron., Jan. 2008, Vol. 55, No. 1, pp. 184-196.

[12] J. Rodriguez, S. Bernet, B. Wu, J. O. Pontt and S. Kouro, "Multilevel Voltage-Source-Converter Topologies for Industrial Medium-Voltage Drives," In: IEEE Trans. Ind. Electron., Dec. 2007, Vol. 54, No. 6 , pp. 2930-2945.

[13] L. G. Franquelo, J. Rodriguez, J. I. Leon, S. Kouro, R. Portillo and M.M. Prats, "The Age of Multilevel Converters Arrives,” In: IEEE Ind. Electron. Magazine, June 2008, Vol. 2, No. 2, pp. 28-39.

[14] Sasi.C and Dr.G.Mohan, "Power Quality Improvement of Grid Connected Wind Energy Conversion System during Transient Fault", International Journal on Energy Conversion, Jan 2013, Vol. 1, No. 1, pp 28-34. 